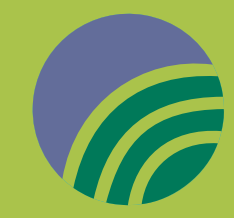

\section{Garrido, Kalinin, Leite, Parrillo, and Stevens to chair 2014 MRS Spring Meeting}

www.mrs.org/spring2014

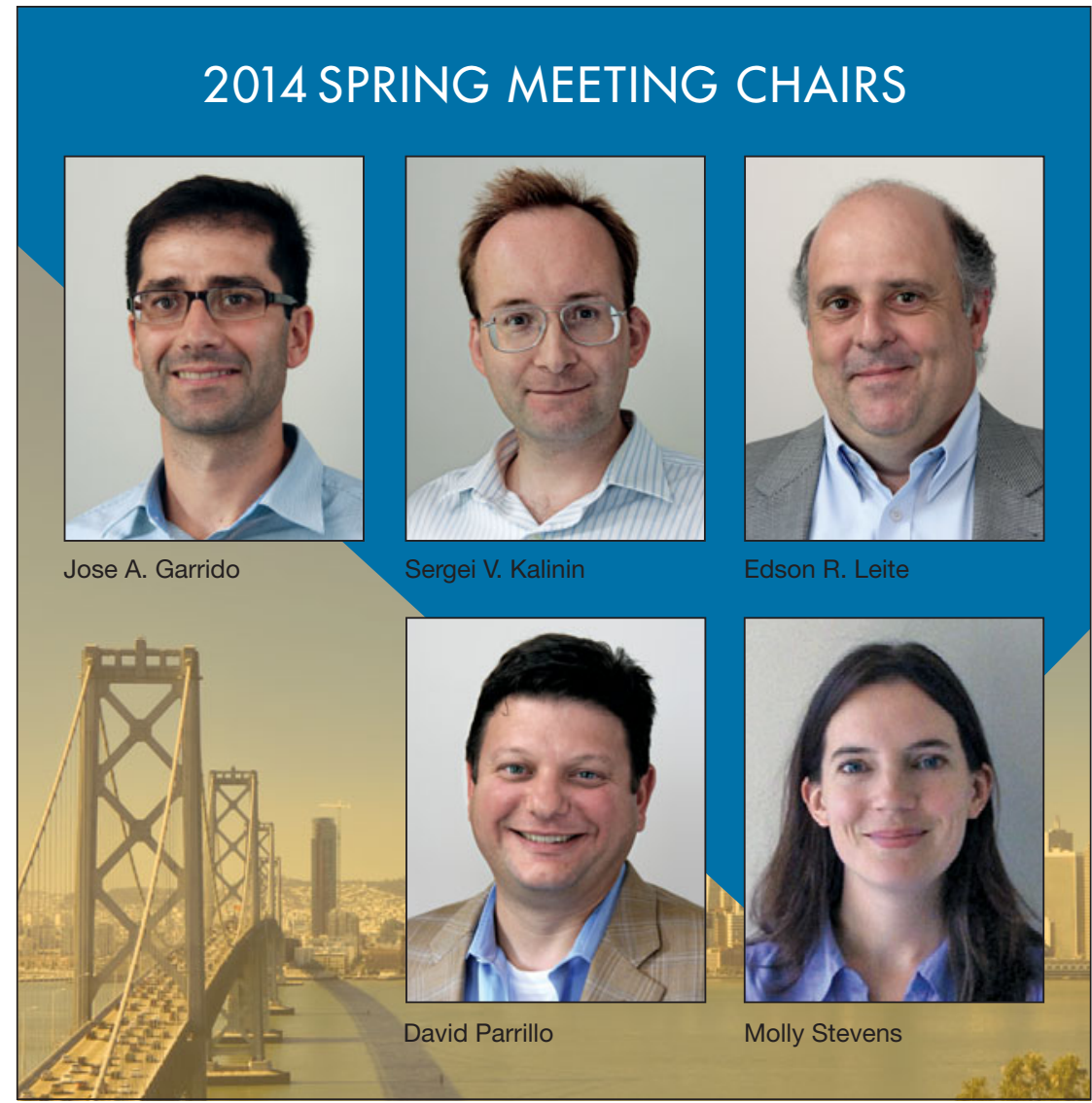

$\mathbf{M}$ eeting Chairs for the 2014 Materials Research Society (MRS) Spring Meeting are Jose A. Garrido (Technische Universität München), Sergei V. Kalinin (Oak Ridge National

\section{MRS} Laboratory), Edson R. Leite (Federal University of São Carlos), David Parrillo (The Dow Chemical Company), and Molly Stevens (Imperial College London). The meeting will be held in San Francisco on April 21-25.

Jose A. Garrido is a senior researcher at the Walter Schottky Institute and the Center for Nanotechnology and Nanomaterials of the Technische Universität München, Germany, where he holds a lecturer position in the Physics Department. He leads the Carbon Functional Materials Research Group, which focuses on the use of various carbon materials such as diamond, graphene, and organic semiconductors for applications in electronics, bioelectronics, and biosensing.

$\mathrm{He}$ received Master's and $\mathrm{PhD}$ degrees in telecommunication engineering from the Technical University of Madrid, Spain, in 1996 and 2000, respectively. From 2001 to 2004, Garrido worked as a postdoctorate at the Walter Schottky Institute, Technische Universität München. He obtained his habilitation in experimental physics in 2010. Since 2011, Gar- rido holds a privatdozent position in the Department of Physics at the Technische Universität München. He co-authored more than 90 scientific publications, including various reviews of diamond and graphene materials for bioelectronics, as well as one book chapter. He has chaired or co-chaired numerous international scientific meetings, including several MRS symposia in the Fall and Spring meetings, and serves on the scientific committee of the major diamond and related materials conferences. Garrido has been the Editor of the journal Diamond and Related Materials since 2011.

Sergei V. Kalinin is currently a senior research staff member at Oak Ridge National Laboratory (ORNL), following a Eugene P. Wigner Fellow appointment at ORNL (2002-2004). He received his $\mathrm{PhD}$ degree (2002) in materials science at the University of Pennsylvania. He is adjunct faculty at The Pennsylvania State University and Sung Kyun Kwan University, and joint associate professor at the Bredesen Center for Interdisciplinary Research and Education at the University of Tennessee, Knoxville.

His research is focused on nano- and atomic-scale physics and electrochemistry of ionically active solids and local bias-induced phase transitions and polarization dynamics in ferroelectric, multiferroic, and macromolecular systems. The key element of his work is scanning probe microscopy (SPM) of electromechanical and transport phenomena. Several of his developments have been adopted and licensed by the SPM industry.

Kalinin's honors include the Presidential Early Career Award for Scientists and Engineers (PECASE) in 2010, Burton Medal of the American Microscopy Society (2010), IEEE-TUFFC Young Investigator Award (2010), the Robert L. Coble (2009) and Ross Coffin Purdy (2003) Awards of the American Ceramic Society, the AVS Peter Mark Memorial Award (2008), and two R\&D100 awards (2010 and 2008). He is the author of more than 300 scientific publications $(h$ $=40$ ) and 14 patents.

Edson R. Leite is a professor in the Chemistry Department at Federal 
University of São Carlos, Brazil, which he joined in 1994. His research interests include synthesis and growth process of inorganic nanoparticles by chemical approaches, materials characterization by electron microscopy, thermal stability of nanostructured materials, and materials for photoelectrochemistry devices and solar water splitting. He received his BS (1988), MS (1990), and PhD (1993) degrees in materials science and engineering from Federal University of São Carlos. In 1988, he was with the 3M of Brazil, where he engaged in the research and development of electronics and telecommunications products. From 1998 to 1999, Leite was Visiting Professor of Materials Science and Engineering at Lehigh University, Pennsylvania. He has published more than 300 scientific papers and one book. Among his honors are the Scopus Prize for the remarkable scientific production from Elsevier/CAPES (2006) and the John Simon Guggenheim Memorial Foundation Fellowship for the development of scientific research related to the thermal stability of a ceramics nanosystem (2009). In 2012, Leite was nominated Member of the World Academy of Ceramics. He is a principal editor of the Journal of Materials Research.

David Parrillo is currently the Global R\&D Director for Packaging and Specialty Plastics at The Dow Chemical Company. Since he joined Dow in 2007, he has developed business strategies for several business platforms for Dow's Technology Licensing \& Catalyst Business, evolved Dow's strategy in the lithium-ion battery market, leading to the formation of the Dow Kokam Joint Venture, and selected and developed the team that defined the strategy to enable the commercial launch of the Dow POWERHOUSETM Solar Shingle. This team received numerous awards, including the 2009 Time Magazine Best 50 Inventions, the 2010 Globe Award, the 2010 Environmental Excellence in Emerging Technology, the 2012 Edison Award for Global Best New Product, and the 2012 Popular Mechanics Breakthrough Award. Additionally, Parrillo championed several innovative Dow venture capital investments within the solar space and has served on the boards of selected investments.

Previously, Parrillo held positions at General Electric and Air Products and Chemicals. He has BS and PhD degrees in chemical engineering from the University of Rhode Island and the University of Pennsylvania, respectively. $\mathrm{He}$ is the holder of 13 US patents and has authored/ co-authored 20 publications in scientific literature. Among his honors are GE's Whitney Technical Achievement Award.

Molly Stevens is a professor of Biomedical Materials and Regenerative Medicine and the Research Director for Biomedical Material Sciences in the Institute of Biomedical Engineering at Imperial College London. In regenerative medicine, her research group focuses on the directed differentiation of stem cells, the design of novel bioactive scaffolds, and new approaches toward tissue regeneration. Recent efforts by her group in biofunctionalized nanoparticles for biosensing have enabled ultrasensi- tive facile protein detection, and have a host of applications across diseases ranging from cancer to global health applications. She joined Imperial College in 2004 after postdoctoral training at the Massachusetts Institute of Technology. Prior to this, Stevens graduated from Bath University with a First Class Honors degree in pharmaceutical sciences and was then awarded a $\mathrm{PhD}$ degree from the University of Nottingham (2000). In 2012, she received the EU40 Award for best materials scientist under 40 in Europe and in 2010, she was recognized by The Times as one of the top 10 scientists under the age of 40 and also received the Polymer InternationalIUPAC Award for creativity in polymer science, the Rosenhain Medal, and the Norman Heatley Prize for Interdisciplinary Research from the Royal Society of Chemistry. Among other honors she has also been recognized by the TR100, a compilation of the world's top innovators under the age of 35 .

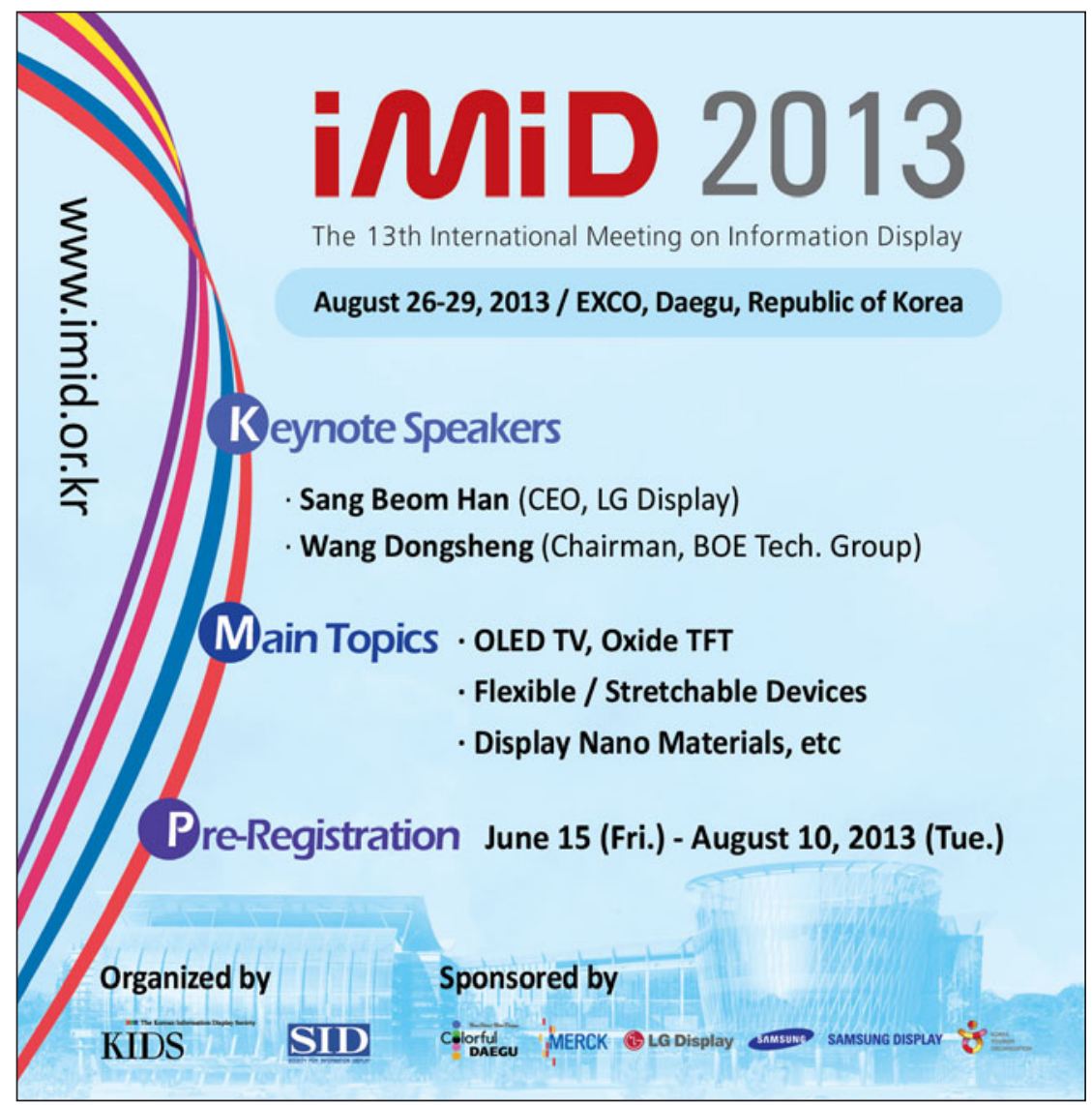

